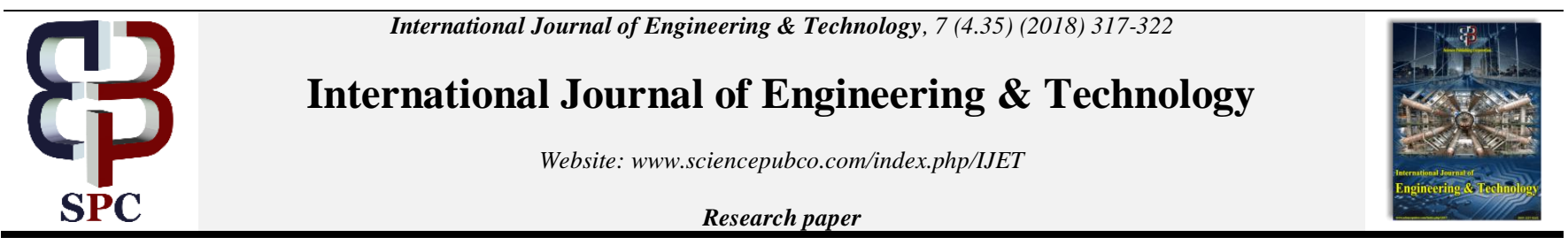

\title{
Experimental Analysis of SMART Scrubbing System with the Principle of Dynamic Precipitation
}

\author{
Nirvenesh Ravindran ${ }^{1}$, Hasril Hasini ${ }^{2}$ * \\ ${ }^{I}$ Department of Mechanical Engineering, Universiti Tenaga Nasional, Jalan Kajang-UNITEN, \\ 43000 Kajang, Selangor, MALAYSIA \\ ${ }^{2}$ Fluid Dynamics and Disaster Risk Management Research Group, Institute of Sustainability Engineering, \\ Universiti Tenaga Nasional, 43000 Kajang, Selangor, MALAYSIA \\ *Corresponding authorE-mail: hasril@ uniten.edu.my
}

\begin{abstract}
This paper presents an experimental investigation of a SMART scrubbing system in sugar processing plant. The objectives are to address the problem and develop new technique to increase the efficiency and eliminate sugar sludge production downstream of process line. The SMART scrubbing effect of water with the principal of dynamic precipitation was conducted on-site with calculated flow rate, which simulates the SMART scrubbing system. The on-site and scaled-down model experiments measure the upstream and downstream dust concentration and processes the flow rate of water required to counter the dust concentration based on the feedback flow. The investigation was conducted with a steady airflow of $6 \mathrm{~m}^{3} / \mathrm{s}$ with variation of water flow rates. The result of the on-site studies shows an excellent increase in average and maximum efficiencies of $98.77 \%$ and $99.3 \%$ respectively.
\end{abstract}

Keywords: dust scrubber, dynamic precipitation, sugar dust management

\section{Introduction}

Food processing of flour and sugar-based plants can create a large amount of dust. This dust, if left untreated can cause health issue to operators and cause safety concern to anyone onsite. In addition, the accumulation of uncontrolled dust can also create operational problem such as the formation of sludge when surrounding humidity increases. Notwithstanding the source, dust from food processing is a challenge that cannot be disregarded. There are approximately 30,000 food-processing facilities that deals with dust-related compound just in the United States.

The manufacturing of sugar involves a process known as sugar drying which is classified in the curing segment of sugar manufacturing [1]. This process dries the sugar to its final product standard, which in return produces a significant amount of sugar dust, which size is about 10 microns. The environment in which the whole process takes place is an enclosed area, which means there is poor ventilation within the vicinity of the factory as there is no human intervention in the process. Thus, currently a simple scrubber system is used with dynamic precipitation. However, after many years in operation, the system is no longer efficient as the precipitation levels are inconsistent with the amount of dust produced. Thus, several important factors need to be taken into account in designing a system in which the dynamic precipitation is directly proportional to the level of dust produced.

A comprehensive review of dust management showed that very limited studies were conducted to reduce dust from its primary source other than the mixers, dry sugar conveyors, coal spalling, etc [2-10]. During the site investigations, it was evident that dryers are the major source of dust produced. In the sugar refining process, the raw sugar is initially washed by mixing it with raw liquor and fine liquor. These processes separate the impurities from the raw sugar, which is then passed through the Ion Exchange Resin (IER) towers where further impurities are removed. After going through a few processes, the moisture content in the sugar will still be high, thus a dryer is used to dry the sugar. This process removes the moisture in the sugar up to $99.9 \%$, thus producing high amount of sugar dust. Therefore, a dynamic precipitation scrubber was installed on site to separate the dust. However, the efficiency of the system is compromised with the production of sludge in the system.

Based on this problem, there is a need to address the issue and develop a new technique to eliminate sludge production in the downstream outlet ducting and increase the efficiency of the system. In the open literature a number of techniques were investigated but these techniques were found to be suitable to specifically defined problems based on plants [11-15]. With this objective in mind, the development of the smart scrubbing effect of water with the principle of dynamic precipitation was proposed. The aim of the SMART system is to reduce the over-precipitation of dust within the scrubber to avoid the production of sludge in the system. The SMART scrubber uses a number of optical dust sensor, which then transmits live data onto a microprocessor, which then determines the flow rate for the dynamic precipitation. The design requirement of the SMART scrubber system was to add an efficient, simple and a feasible unit addition to the existing scrubber system to reduce the cost of the system.

\section{SMART Scrubber System}

The basic scrubber system consists of an air-powered upstream venturi, a water jet spray and a downstream ducting. During the experiments, which was conducted on site, a steady volumetric airflow of $6 \mathrm{~m}^{3} / \mathrm{s}$ was maintained. With the addition of the feed- 
back loops, the current dust absorption system is able to be made automatic with respect to the level of dynamic precipitation produced as shown in the experimental rig. The proposed scrubber system can be used for any application of scrubbing of fine particles such as sugar dust, coal dust, etc. With the SMART scrubber, the system needs very low maintenance and is safe for use in thorough conditions as there is no dynamic parts involved. The dust measurement technique by using a dust sensor which works on the principle of the dust lamp [4], also further optimizes the cost in dust concentration measurement

The initial cause of the over precipitation of dust in the system was due to the lack of innovation within the system to measure the dust variation that enters the system. Thus, a single flow rate of jet spray was used to precipitate a high and a low concentration of dust in the upstream part of the system.

\section{Methodology}

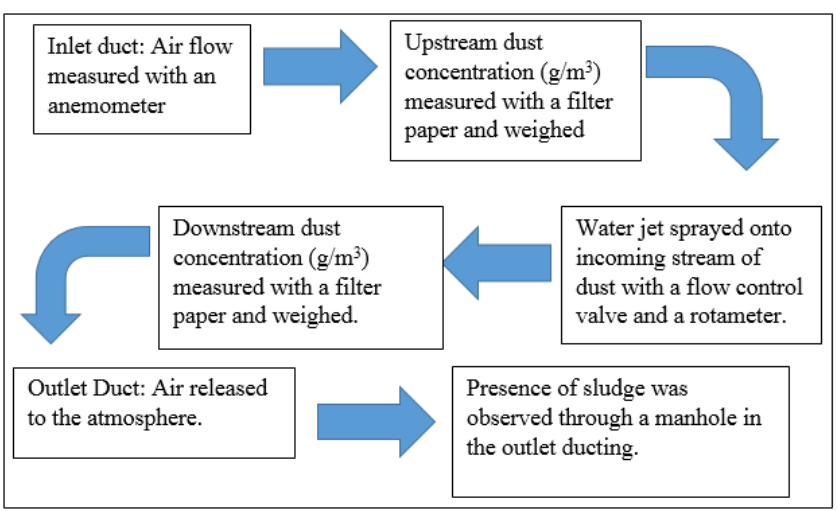

Fig 1: Flow Diagram of the Scrubber system

The study is conducted in stages and the flow of activity is shown in Fig. 1. At the inlet duct, air flow was measured with an anemometer. Then the dust concentration is also measured using a filter paper. Further downstream of the flow channel, water jet was sprayed onto the incoming mixture stream with a flow control valve and rotameter. The amount of water jet sprayed into the steam is very critical to ensure that most of the dust is captured and at the same time, formation of sludge can be minimized, if not eliminated. In general, the objective is accomplished in the following strategies:

\subsection{On Site Experimental Set Up}

Figs. 2 and 3 show the on-site configuration and schematic diagram of the system under investigation respectively. The system was fed by a number of high dust producing equipment such as the dryers, dry sugar conveyors and several other conveyors at the inlet of the scrubber ducting in stages to increase the dust concentration based on the water flow rate. The concentration of dust from these systems range between $102.50\left(\mathrm{~g} / \mathrm{m}^{3}\right)$ to $208.64\left(\mathrm{~g} / \mathrm{m}^{3}\right)$. The concentration of dust was measured with the conventional method of using a filter paper and weighing scale. Due to the potential inaccuracy of the method used, 5 samples were tested for each flow rate to obtain the appropriate efficiency of the scrubber system. The system has a constant airflow of $6.0 \mathrm{~m}^{3} / \mathrm{s}$. The water flow rate ranges from 2 to $5 \mathrm{~m}^{3} / \mathrm{hr}$.

Based on on-site operation feedback, the objective of this study is not only to eliminate the dusts within the system, but also not to produce any moisture content at the outlet duct. The presence of moisture at the outlet duct of the system was also noted in order meet the objective of the smart dynamic precipitation system.

\subsection{On-Site Experiment of Dust Concentration}

There are many ways to measure the concentration of dust in air. Most commonly used, an optical test is usually done to measure the scattered light beam in dust. The method employed in the development of the SMART scrubber is the filter test method for rapid weight distribution, the analysis of this method is gravimetric. It is not only inexpensive but it is the procedure most generally accepted at present and such analytical techniques are relatively simple. A filter paper type of Composite Filter PG-60 specially developed for the measurement of dust concentration in air was used. The filter papers are also PTFE coated, thus being naturally hydrophobic and unaffected by humidity. The following steps are taken for the measurement:

(i). Each filter paper was weighed on an analytical balance before use, and noted as, $w 0$

(ii). A filter paper holder was used to hold the filter paper in place in the inlet and outlet duct.

(iii). The filter paper was left in the duct for 60 seconds.

(iv). The filter paper was again weighed on an analytical balance and noted as, $w 1$

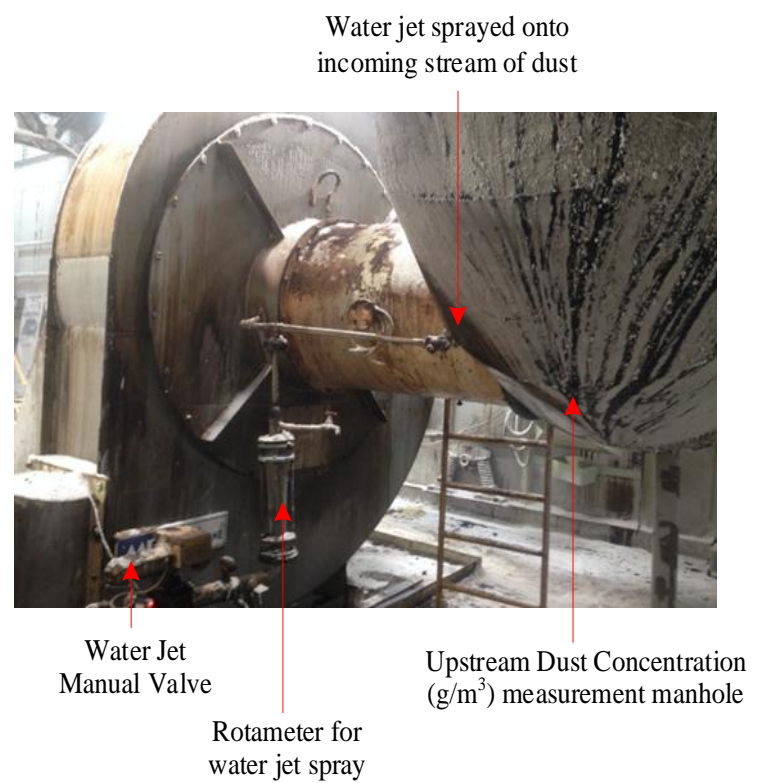

Fig 2: On-site configuration of scrubber system

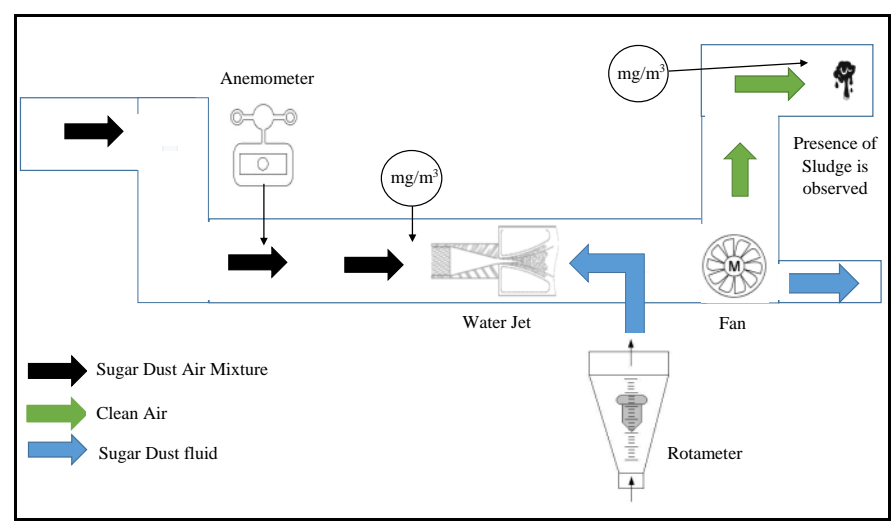

Fig 3: Schematic diagram of the on-site scrubber system

From the measurement, the concentration of sugar dust can be determined using Eq. 1.

$$
C=\frac{\dot{m}_{S}}{\dot{V}}
$$


Where $C, \dot{m}_{s}$ and $\dot{V}$ are the concentration, mass flow rate of sugar and volume flow rate respectively.

\subsection{Scrubber Efficiency}

In the scrubber system, the ratio of dust concentration at the inlet and outlet duct are used to measure the efficiency of the scrubber. For the purpose of this work, the scrubbing efficiency, $\eta_{S}$ is differentiated from the dust elimination efficiency, $\eta_{D}$ due to the presence of sludge. The presence of sludge is known to reduce the efficiency of the scrubber by $50 \%$.

$$
\begin{aligned}
& \eta_{D}=\frac{C_{U}-C_{D}}{C_{D}} \\
& \eta_{S}=\eta_{D}-0.5
\end{aligned}
$$

\subsection{Water Flow}

One of the aims of this work is to regulate the flow rate of water based on the inlet dust density. Thus, it is valid and practical to say that the flow rate of water equals to the dust concentration. The flow rate of water $\left(\mathrm{m}^{3} / \mathrm{hr}\right), \dot{m}_{w}$ takes the form:

$$
\dot{m}_{w}=\dot{V} C_{U}
$$

Fig. 4 shows the scaled-down model of the system. The test rig consists of an inlet and outlet ducts, is powered by a fan, which produces suction. The location of the photo sensors is also shown and they are located close to the water spray point. This is to ensure accurate measurement of captured dust. The photo sensors are connected to microcontrollers in order coordinate the whole operation of the smart scrubbing effect.

Two arrangements of photo sensors are implemented in the smart scrubbing effect with water precipitation as shown in Fig. 5. There are:

(i). Equidistant arrangement: 1 light source, 2 photo sensors

(ii). Perpendicular arrangement: 2 light source, 2 photo sensors

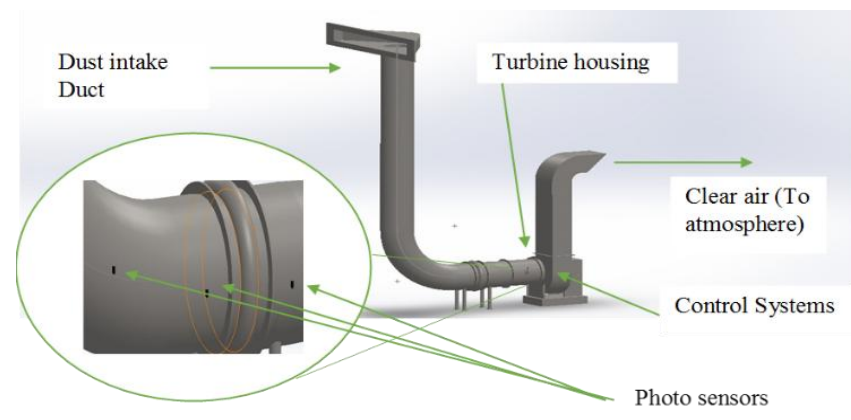

Fig 4: Design of on-site experimental rig

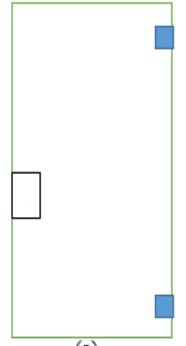

(a)

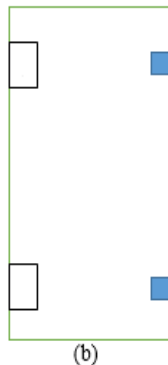

(b)
Fig 5: (a) Equidistant arrangement, (b) Perpendicular arrangement of light source and photo sensor

\subsection{Scaled-Down Experimental Analysis}

The scaled-down experimental rig is fabricated to test the proposed dust controlled mechanism and proof of concept for the SMART scrubber system. This is shown in Fig. 6. The open system model was constructed with a feedback loop from a dust sensor, which works on the same principle as a dust lamp. External dust is fed into the system through a vertical funnel at the input duct. The dust sensor is then used to measure the concentration of dust, which is then transmit the live data onto an Arduino microcontroller, which outputs a regulated flow rate. A dust sensor at the output ducting is used to justify the output dust concentration. Arduino UNO was programmed to receive voltage signals from a photo transducer. These voltage signals are then converted into dust density which is reflected by $(\mathrm{g} / \mathrm{sec})$ in the serial monitor of the Arduino. The dust density is then mapped on to a set of Pulse Width Module signals which range from $0-255 \mathrm{~Hz}$. The Pulse Width Module is used to control the pump, which in turn regulates the flow rate of water entering into the system.

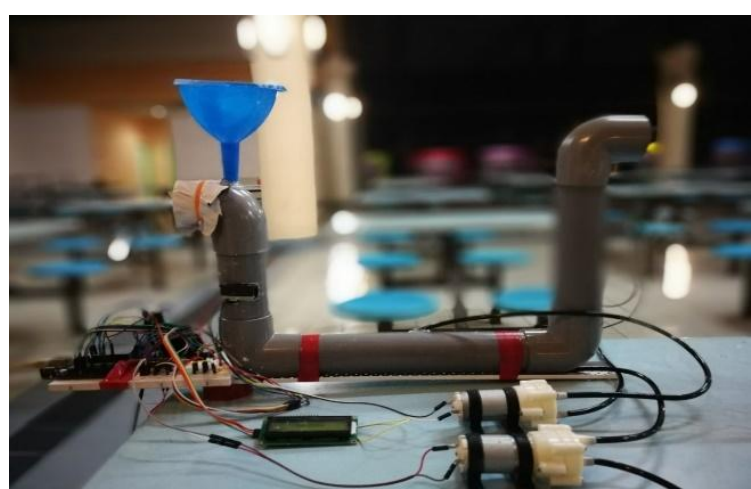

Fig 6: Experimental Rig Set-Up

\section{Result, Analysis and Discussion}

\subsection{On-Site Test Analysis of Dust Concentration}

During the on-site testing, the volumetric air flow rate is fixed at 6 $\mathrm{m}^{3} / \mathrm{s}$ while the water flow rate varies. Then the result for scrubbing efficiency is recorded. Prior to the test, an error analysis is carried out to ensure accurate measurement of water and air flow rates. This is due to the fact that the control devices used in the existing manufacturing plants were very old and there might be discrepancies from wear and tear from valves etc. Also, the digital flowmeter placement at the outlet duct needs to be evaluated for accuracy. To ascertain this, theoretical flow calculation is carried out and compared with the actual measurement for different water flow rates. The comparison shows minimal errors and this is illustrated in Fig. 7.

Fig. 8 shows the average scrubbing efficiency and dust eliminated at different water flow rates. It shows that the efficiency of the scrubber is highly dependent on the water/dust concentration ratio. The quantity of water is directly proportional to the concentration of dust. A high amount of water to a low amount of dust concentration would result in production of sludge at the outlet duct of the scrubber. The efficiency of the scrubber was further reduced by $50 \%$ with the production of sludge. Based on the comparison of flow rate $(1 / \mathrm{min})$, the average scrubbing efficiency and percentage of dust eliminated, it can be seen that the higher the flow rate of water, the lower the scrubbing efficiency. This is evident although the percentage of dust eliminated in the system increases with the flowrate due to the production of sludge.

Measurement of dust concentration at both upstream and downstream channel is shown in Fig. 9. It can be seen that the dust elimination efficiency is high for all water flow rates. Although dust elimination efficiency is high, production of sludge at outlet duct reduces the scrubbing efficiency by almost $50 \%$. This shows 
that an increase in water flowrate would increase the efficiency of dust elimination at downstream, but careful attention needs to be taken as this practice also promotes an increase production of sludge.

Test are also carried out for cases with different flow rate of water, i.e. $2 \mathrm{~m}^{3} / \mathrm{hr}$., $3 \mathrm{~m}^{3} / \mathrm{hr}$., $4 \mathrm{~m}^{3} / \mathrm{hr}$., and $5 \mathrm{~m}^{3} / \mathrm{hr}$. (with a fixed air flow). The results are illustrated in Figs. 10-13 respectively. At water flow

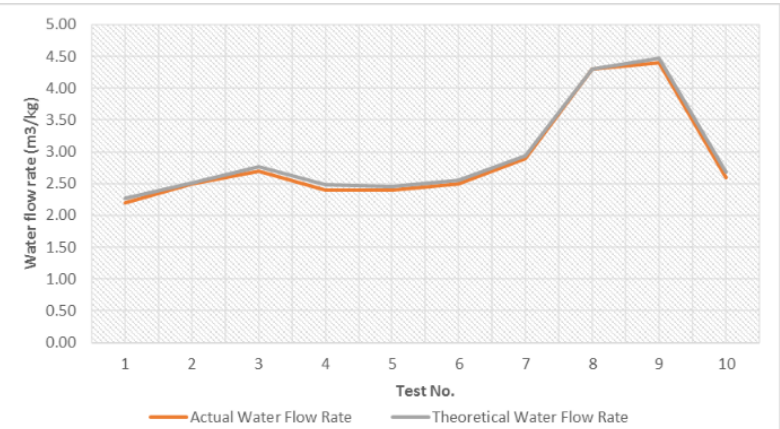

Fig 7: Theoretical water flow rate against actual water flow rate $\left(\mathrm{m}^{3} / \mathrm{hr}\right.$. $)$

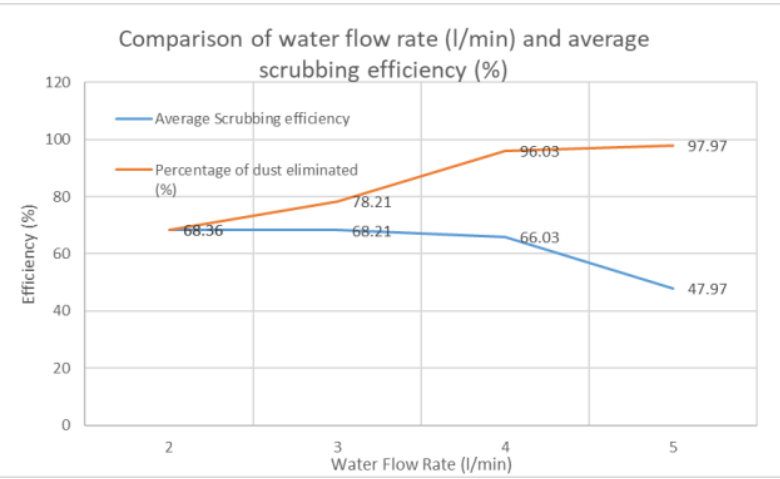

Fig 8: Comparison of water flow rate (1/min) and average scrubbing efficiency $(\%)$

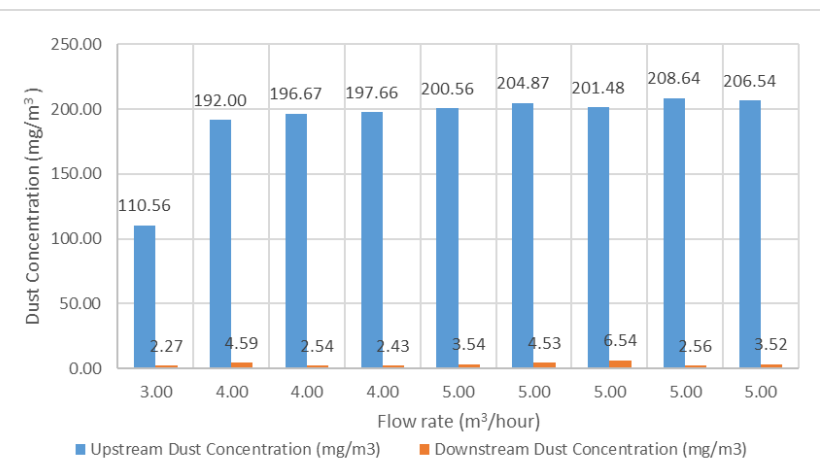

Fig 9: Dust concentration at upstream and downstream of duct.

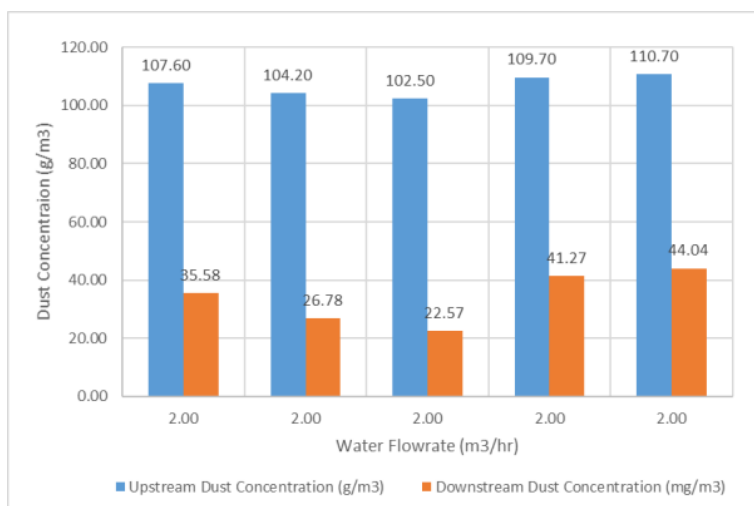

Fig 10: Dust concentration against the water flowrate of $2 \mathrm{~m}^{3} / \mathrm{hr}$.

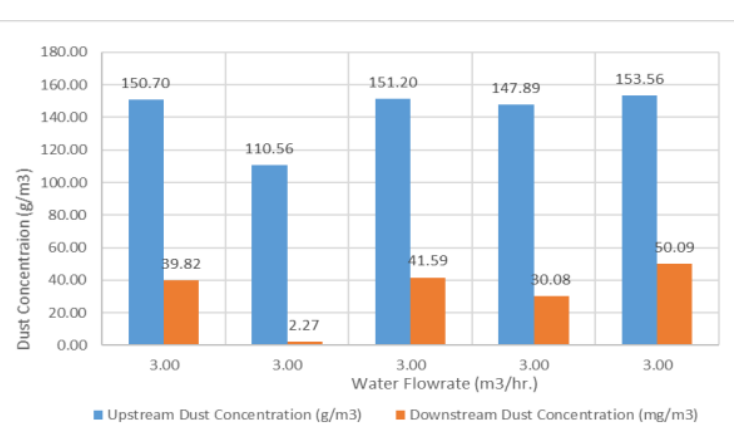

Fig 11: Dust concentration against the water flowrate of $3 \mathrm{~m}^{3} / \mathrm{hr}$.

rate of $2 \mathrm{~m}^{3} / \mathrm{hr}$., the percentage of dust eliminated in the downstream scrubber is approximately $68 \%$. Although the percentage of dust eliminated in the system is the lowest compared to other cases with higher flow rates, the efficiency of the scrubber remains the highest. The low dust elimination at this flowrate is due to inadequate amount of water that is supplied to the system causing incomplete precipitation of dust. The efficiency of the scrubber however depends on the production of sludge at the outlet duct of the system, at low flowrate and incomplete precipitation of dust in the system; it is obvious that sludge production is the lowest.

At increased water flow rates of $3 \mathrm{~m}^{3} / \mathrm{hr}$. and $4 \mathrm{~m}^{3} / \mathrm{hr}$., a steady increase of percentage of dust eliminated is noted, although the opposite is noted in the scrubber efficiency. The scrubber efficiency has steadily declined from $68 \%$ to $66 \%$ at these flowrates respectively. This is due to over precipitation of dust, which causes moisture to be present at the outlet duct of the scrubber system. Over precipitation of dust drastically reduces the efficiency of the scrubber by almost $50 \%$.

At flowrate of $5 \mathrm{~m}^{3} / \mathrm{hr}$., it can be seen that over precipitation of the dust increases the percentage of dust eliminated to $98 \%$. Almost all the dust in the duct is successfully trapped by the filter. However, large amount of injected water has caused large sums of sludge to be accumulated in the downstream system.

Based on the results presented, it can be seen that with adequate and precise amount of water, the production of sludge in the outlet duct of the scrubber can be avoided. The average achievable efficiency from the scrubber system is $98 \%$. This is also coherent with the proposed theory varying the flow rate based on the dust concentration.

\subsection{Scaled-Down Experiment}

In the scaled down experiment, powdered particle is used to emulate sugar dust, which is injected at inlet duct. The dust concentration (termed density for scaled-down experiment) was slowly increased from $0.25 \mathrm{~g} / \mathrm{m}^{3}$ until a terminal capacity of $0.66 \mathrm{~g} / \mathrm{m}^{3}$. Photo transducers are placed upstream and downstream of the duct to capture the density. These sensors were initially calibrated based on known dust densities prior to the experiment. The motor bandwidth was also directly mapped to the upstream dust density from a range of $0-255$ on the Pulse Width Module (PWM) scale. The variation of inlet dust density against water flow rate is linear as shown in Fig. 14.

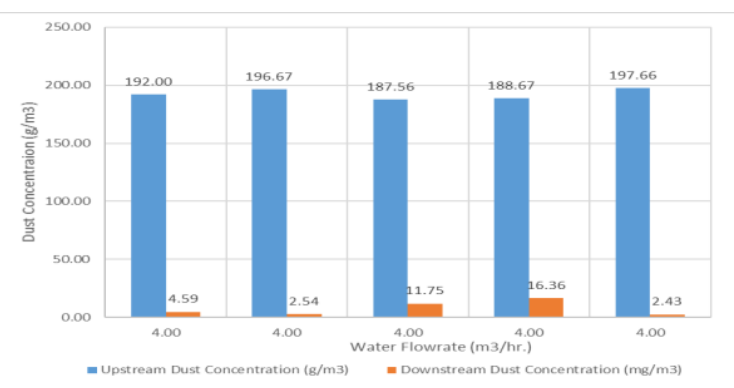

Fig 12: Dust concentration against the water flowrate of $4 \mathrm{~m}^{3} / \mathrm{hr}$. 


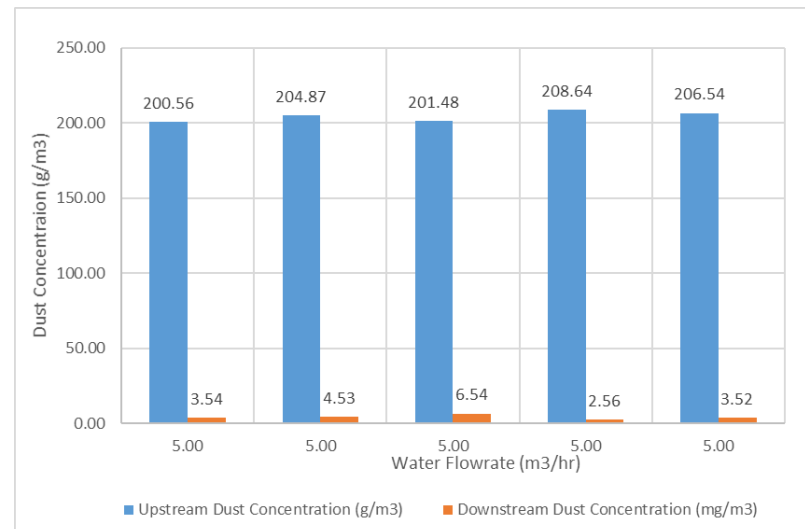

Fig 13: Dust concentration against the water flowrate of $5 \mathrm{~m}^{3} / \mathrm{hr}$.

Assessment of dust density at duct inlet and outlet is illustrated in Fig. 15. Similar behaviour is shown with the on-site measurement The amount of dust measured at the outlet is significantly reduced for all water flow rates. Despite showing linear increase of dust concentration at the inlet, the outlet measurement of dust density does not show a linear trend. This can be attributed to the influence of water which reacts with the dust forming sludge at the exit. During this process, no clear trend is indicated as the process is unpredictable. Thus, for the scaled-down test, no clear trend can be concluded in terms of dust removal efficiency as illustrated in Fig. 16. Scaled-down experimental rig also shows a clear proof of concept, in terms of dust elimination using filtered paper. The efficiency of the system is also clearly seen to be peaked at over 99\%. Thus it can be said that the SMART scrubber is very efficient to be applied under controlled industrial conditions.

\section{Conclusion}

On-site experiment and scaled-down model testing of SMART scrubber system to reduced sugar dust concentration has been investigated. The objective is to develop a SMART scrubber system capable of removing sugar dust in a sugar manufacturing plant and at the same time, minimize the production of sludge at duct outlet. On site investigation shows that the average efficiency of the SMART scrubber is $98 \%$ with a maximum achievable efficiency of $99.4 \%$. This corresponds to an upstream dust concentration of $198.54 \mathrm{~g} / \mathrm{m}^{3}$ and downstream dust concentration $1.26 \mathrm{~g} / \mathrm{m}^{3}$ with no presence of moisture or sludge. This is a vast improvement of efficiency from the existing system (which has an average efficiency of $60 \%$.). The result has demonstrated the capability of SMART scrubbing system to remove sugar dust with maximum efficiency and at the same time minimize sludge formation.

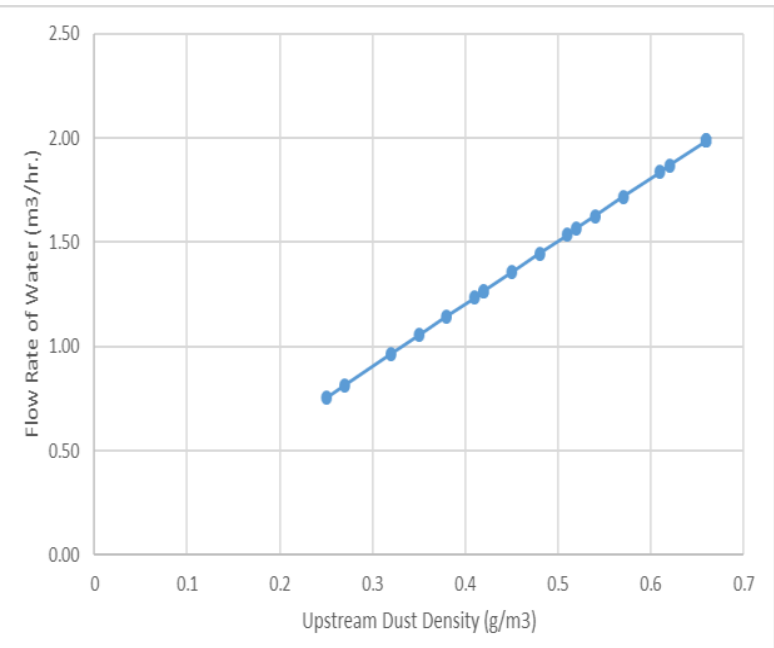

Fig 14: Upstream Dust Density against the flow rate of water

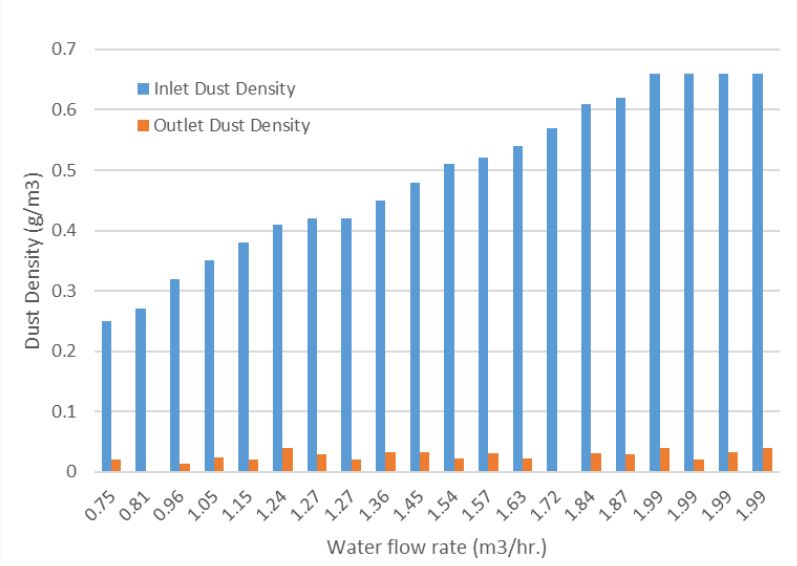

Fig 15: Inlet and outlet dust density against water flow rate

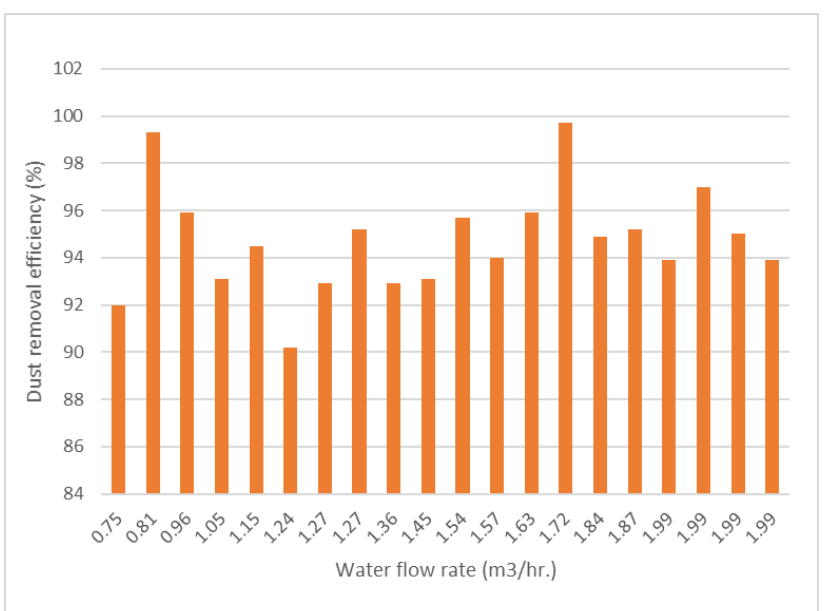

Fig 16: Dust removal efficiency against water flow rate

\section{Acknowledgement}

This work is supported by MSM Prai Berhad and Universiti Tenaga Nasional. The authors would also like to acknowledge the financial assistance received from UNITEN Internal Research Grant (UNIIG) that enable the work to be carried out.

\section{References}

[1] Thorn, Jonathan, Mike Althouse, D.C.: Safe Handling of Sugar Refinaries and Consumers. (2008)

[2] Yue, H., He, C., Zhao, Y., Ma, Q., Zhang, Q.: The brightness temperature adjusted dust index: An improved approach to detect dust storms using MODIS imagery. International Journal of Applied Earth Observation and Geoinformation. 57, 166-176 (2017). doi:10.1016/j.jag.2016.12.016

[3] Hoeflinger, W., Laminger, T.: PM2.5 or respirable dust measurement and their use for assessment of dust separators. Journal of the Taiwan Institute of Chemical Engineers. 0, 1-9 (2017). doi:10.1016/j.jtice.2017.07.035

[4] Lay-Ekuakille, A., Ciaccioli, A., Griffo, G., Visconti, P., Andria, G.: Effects of dust on photovoltaic measurements: A comparative study. Measurement: Journal of the International Measurement Confederation. 113, 181-188 (2018) doi:10.1016/j.measurement.2017.06.025

[5] Talbot, A.: Measuring and Managing Particulates and Dust - Technical and Practical Issues. (2010)

[6] Nakao, Y., Horiguchi, N., Yoshida, H., Kanagawa, T., Kaneko, A., Abe, Y.: Measurement of flow rate of droplets and liquid film in venturi scrubber. International Conference on Nuclear Engineering, Proceedings, ICONE. 4, 1-4 (2016). doi:10.1115/ICONE24-60641

[7] Dinh, T.V., Choi, I.Y., Son, Y.S., Kim, J.C.: A review on nondispersive infrared gas sensors: Improvement of sensor detection limit and interference correction, (2016) 
[8] Li, X., Wei, T., Wang, D., Hu, H., Kong, L., Xiang, W.: Study of gas-liquid two-phase flow patterns of self-excited dust scrubbers. Chemical Engineering Science. 151, 79-92 (2016). doi:10.1016/j.ces.2016.05.010

[9] Ali, H., Plaza, F., Mann, A.: Flow visualization and modelling of scrubbing liquid flow patterns inside a centrifugal wet scrubber for improved design. Chemical Engineering Science. 173, 98-109 (2017). doi:10.1016/j.ces.2017.06.047

[10] Mi, T., Yu, X.M.: Dust removal and desulphurization in a novel venturi scrubber. Chemical Engineering and Processing: Process Intensification. 62, 159-167 (2012). doi:10.1016/j.cep.2012.07.010

[11] K.A., V., Hareendran, M.: Coal dust exposure reduction using water mist system: A case study. Journal of Chemical Health and Safety. 1-5 (2017). doi:10.1016/j.jchas.2017.10.003

[12] Wang, X., Zhu, P., Li, Y., Ni, X., Fan, M.: Effect of low ambient air pressure on spray characteristics of water mist. Experimental Thermal and Fluid Science. 66, 7-12 (2015) doi:10.1016/j.expthermflusci.2015.03.009

[13] Antczak-Chrobot, A., Bąk, P., Wojtczak, M.: The use of ionic chromatography in determining the contamination of sugar byproducts by nitrite and nitrate. Food Chemistry. 240, 648-654 (2018). doi:10.1016/j.foodchem.2017.07.158

[14] Metzler, P., Weiß, P., Büttner, H., Ebert, F.: Electrostatic enhancement of dust separation in a nozzle scrubber. Journal of Electrostatics. 42, 123-141 (1997). doi:10.1016/S0304-3886(97)00135-6

[15] Wang, Q., Wei, W., Gong, Y., Yu, Q., Li, Q., Sun, J., Yuan, Z. Technologies for reducing sludge production in wastewater treatment plants: State of the art. Science of the Total Environment. 587-588, 510-521 (2017). doi:10.1016/j.scitotenv.2017.02.203 